\title{
ОПРЕДЕЛЕНИЕ КОЛИЧЕСТВА ОБЪЕКТОВ ДЛЯ ПРОВЕДЕНИЯ ЭКСПЛУАТАЦИОННЫХ ИСПЫТАНИЙ ВАГОННОЙ ТЕХНИКИ
}

\section{DETERMINATION OF THE AMOUNT OF OBJECTS FOR OPERATIONAL TEST EQUIPMENT WAGONS}

\author{
Представил д-р техн. наук, профессор С.В. Мямлин
}

\begin{abstract}
Введение. В статье рассмотрены вопросы формирования планов эксплуатационных испытаний образцов новой вагонной техники, методики определения минимального числа объектов наблюдений для износовых отказов деталей вагона; проведен расчет необходимого количества опытных образцов вагонной техники, которые носят износовый характер в эксплуатации для исследования их показателей надежности; описаны цели, задачи и объекты исследования эксплуатационных свойств надежности узлов и деталей грузовых вагонов в составе опытных маршрутов; приведены примеры образцов новой вагонной техники, которые находятся в эксплуатации на опытных маршрутах Укрзализныци.
\end{abstract}

Цель работы. Обоснование минимального количества объектов, необходимых для проведения эксплуатационных испытаний.

Результаты. Сформирована методика определения минимального количества объектов для проведения эксплуатационных испытаний некоторых деталей и узлов вагонов. На основе приведенной в статье методики определено минимальное количество железнодорожных колес для получения обоснованных показателей надежности в условиях эксплуатации.
Выводы. Приведенная методика расчета необходимого количества опытных узлов и деталей вагонов для формирования их показателей надежности может быть предложена для практического применения.

Изложение основного материала. Научно-технические проблемы исследований надежности технических систем продолжают быть актуальными.

Одной из самых важных задач, которые предъявляются к подвижному составу железных дорог, является повышение надежности, увеличение ресурса узлов и деталей, что требует создания новых или совершенствования старых образцов вагонной техники.

В соответствии с государственным стандартом [1] надежность как понятие определено в следующей редакции: «Надежность объекта (изделия) - свойство объекта сохранять во времени в установленных пределах значения всех параметров, характеризующих способность выполнять требуемые функции в заданных режимах и условиях применения, технического обслуживания, хранения и транспортирования».

Надежность контролируется на всех этапах создания новых образцов техники, в том числе и во время эксплуатационных испытаний, при которых накапливаются 
статистические данные об их износах, отказах и повреждениях.

Сбор и первичная обработка информации с учетом дальнейшей полной математической обработки о надежности вагонов должна обеспечить:

- получение сопоставимых и объективных данных о надежности вагонов и его составных частей;

- возможность обобщения результатов обработки информации о надежности.

Сбор и обработка информации о надежности вагонов должна производиться с целью получения достоверных данных, обеспечивающих возможность и проведения:

- конструктивных усовершенствований с целью повышения надежности;

- усовершенствований технологии изготовления, сборки, контроля и испытаний, направленных на обеспечение требуемого уровня надежности;

- организационно-технических мероприятий, направленных на соблюдение правил эксплуатации, повышения эффективности технического обслуживания, повышения качества ремонта и оптимизации затрат на его проведение.

Статистическая информация о надежности и техническом состоянии вагонов должна обеспечить возможность решения следующих задач:

- определение причин возникновения отказов и неисправностей;

- установление и корректировка нормируемых показателей надежности;

- выявление систем, агрегатов, узлов и деталей, лимитирующих надежность вагонов;

- определение номенклатуры и количества запасных частей и материалов;

- выявление влияния условий и режимов эксплуатации на надежность;

- определение экономической эффективности от повышения надежности деталей и узлов вагонов.
Как правило, испытания на надежность как отдельных узлов и деталей, так и вагона в целом представляет определенные значительные трудности, связанные с большими затратами на их проведение. При этом имеется сложность в имитации действительных нагрузок и внешних условий при проведении испытаний.

Первичные данные о надежности вагонов могут быть получены путем проведения испытаний на безотказность, долговечность, ремонтопригодность или наблюдений в процессе непосредственной эксплуатации.

Наиболее полные и достоверные данные о надежности могут быть получены при эксплуатации вагонов.

В отрасли вагоностроения для оценки надежности вагонов, его систем и узлов, как правило, используются данные, полученные по результатам их эксплуатации в реальных условиях. При этом эксперимент носит пассивный характер. Это приводит к тому, что план испытаний обосновывается на основе полученной информации.

Опыт сбора и обработки информации о надежности вагонов [2] показал, что наиболее употребительными начальными планами наблюдений являются:

- [NUT] - план испытаний, согласно которому одновременно испытывают $\mathrm{N}$ объектов; отказавшие во время испытаний не восстанавливают и не заменяют, испытания прекращают по истечении времени испытаний или наработки Т для каждого неотказавшего объекта;

- $[\mathrm{NRT}]$ - план испытаний, согласно которому одновременно испытывают $\mathrm{N}$ объектов; отказавшие во время испытаний заменяют новыми, испытания прекращают по истечении времени испытаний или наработки Т для каждого объекта;

- [NUN] - план испытаний, согласно которому одновременно испытывают $\mathrm{N}$ объектов; отказавшие во время испытаний не восстанавливают и не заменяют, 
испытания прекращают по выходу из строя всех объектов.

Причем планы [NUT], [NRT] являются однократно усеченными. План [NUN] используется для малонадежных элементов или элементов, срок службы которых меньше периода наблюдения. При необходимости использования других планов наблюдения и законов распределений следует обратиться к работам [3, 4].

Для облегчения проведения расчетов в таблице приведены типы законов распределения наработки на отказ для отдельных узлов грузового вагона.

Таблица

Законы распределения наработки на отказ вагона и его отдельных узлов

\begin{tabular}{|c|c|c|}
\hline $\begin{array}{l}\text { № } \\
\Pi / \Pi\end{array}$ & $\begin{array}{c}\text { Наименование } \\
\text { сборочной единицы }\end{array}$ & $\begin{array}{c}\text { Тип } \\
\text { распределения }\end{array}$ \\
\hline 1 & Колесная пара (выщербины, ползуны) & Экспоненциальный \\
\hline 2 & $\begin{array}{l}\text { Наработка между первым и вторым отказами } \\
\text { вагона (все виды отказов) }\end{array}$ & Экспоненциальный \\
\hline 3 & $\begin{array}{l}\text { Наработка между вторым и третьим отказами } \\
\text { вагона (все виды отказов) }\end{array}$ & Экспоненциальный \\
\hline 4 & Наработка на отказ вагона (все виды отказов) & Вейбулла \\
\hline 5 & $\begin{array}{l}\text { Ходовые части (износостойкие отказы, отказы } \\
\text { усталостного характера) }\end{array}$ & Нормальное распределение \\
\hline 6 & $\begin{array}{l}\text { Наработка на отказ сборочных единиц в период } \\
\text { приработки }\end{array}$ & Вейбулла \\
\hline 7 & $\begin{array}{l}\text { Наработка на отказ сложной системы, } \\
\text { состоящей из большого числа } \\
\text { восстанавливаемых объектов }\end{array}$ & Экспоненциальный \\
\hline
\end{tabular}

При этом функции распределения в зависимости от закона распределения наработки на отказ [3] имеют следующий вид:

- экспоненциальный

$$
f(t)=\lambda e^{-\lambda t}
$$

- нормальное распределение

$$
f(t)=\frac{1}{\sigma \sqrt{2 \pi}} e^{-\frac{(t-a)^{2}}{2 \sigma^{2}}}
$$

- Вейбулла

$$
f(t)=\frac{b}{a}\left(\frac{t}{a}\right)^{b-1} \cdot e^{-\left(\frac{t}{a}\right)^{b}} .
$$

Используя вышеуказанные зависимости, определим необходимое количество колесных пар для исследования износа гребней колес в эксплуатации, которые носят износовый характер. Предполагаем, что закон распределения их наработок до первого отказа - нормальный (см. таблицу). В этом случае коэффициент вариации согласно работе [4] равен 0,6. Подставляя исходные данные в формулу (2) или используя табл. 6 прил. 1 [5], находим $\mathrm{N}=78$ колес, т. е. для проведения исследований износостойкости гребней колес в эксплуатационных испытаниях должно участвовать не менее 39 колесных пар с опытными колесами.

С целью формирования характеристик надежности как вагонов в 
целом, так и отдельных узлов и деталей вагонов приказом по УЗ сформированы опытные маршруты сообщением Роковатая - Ужгород - Кошице с длиной одного рейса 2700 км. Работа вагонов в составе маршрута предусматривает загрузку их рудой при помощи экскаваторов или погрузочных бункеров на железорудных комбинатах Криворожья и разгрузку на роторных вагоноопрокидывателях Словакии (на металлургическом комбинате Кошице). Коэффициент порожнего пробега при этом составляет 0,5.

На основании собранных данных выполняются необходимые расчеты [6, 7], которые позволяют построить прогнозы ресурса исследуемых образцов.

За более чем 40 лет существования опытных маршрутов были выполнены многочисленные исследования эксплуатационной надежности различных образцов вагонной техники. Так, недавно завершены сравнительные испытания тормозных колодок производства ООО «Трибо» (г. Белая Церковь) и производства фирмы RFPS (США), что позволило сделать выводы о целесообразности применения исследуемых колодок на железных дорогах Украины.

В настоящее время продолжается опытная эксплуатация вагонов нового поколения 18-7023-01 на тележках 12-7020 производства ОАО «КВСЗ». Результаты первой части испытаний были использованы при решении о серийном производстве данных вагонов. В декабре 2010 года вагонам был выполнен первый деповской ремонт после постройки, а в настоящее время исследуется эксплуатационная надежность вагонов нового поколения после деповского ремонта.

Кроме того, в опытных маршрутах испытываются новые втулки в шарнирах рычажной передачи; фрикционные клинья, восстановленные по новой технологии; безрезьбовое соединение в тормозной магистрали; биметаллические подшипники в пятниковом узле, литые колеса производства США; ходовые части тележки модели 18-100, модернизированные по технологии «А.Стаки».

Выводы. Таким образом, в статье приведена методика по определению минимального количества объектов в эксплуатационных испытаниях деталей и узлов вагонов, имеющих характер естественного износа. На основе данной методики пределено минимальное количество железнодорожных колес для получения их показателей надежности в эксплуатации.

Испытания в составе маршрутов «Роковатая - Ужгород - Кошице» позволяют оценить эксплуатационные свойства опытных образцов новой техники, сформировать выводы о целесообразности их производства и использования на железных дорогах.

\section{Список литературь}

1. ГОСТ 27.002-89. Надежность в технике. Основные понятия. Термины и определения [Текст]. - Введ. 15.11.89. - М.: Транспорт, 1990. - 32 с.

2. Нагруженность элементов конструкции вагонов [Текст] / под ред. В.Н. Котуранова. М.: Транспорт, 1991. $-238 \mathrm{c.}$

3. ГОСТ 27.410-87. Надежность техники. Методы контроля показателей надежности и планы контрольных испытаний на надежность [Текст]. - М.: Изд-во стандартов, 1988. - 110 с.

4. ДСТУ 3004-95. Надійність техніки. Методи оцінки показників надійності за експериментальними даними [Текст]. - Введ. 01.01.96. - К.: Держстандарт України, 1995. $123 \mathrm{c}$.

5. ГОСТ 17510-72. Надежность изделий машиностроения. Система сбора и обработки информации. Планирование наблюдений [Текст]. - М.: Изд-во стандартов, 1971. - 20 с. 
6. Савчук, О.М. Эксплуатационные испытания полувагонов нового поколения [Текст] / О.М. Савчук [и др.] // Вагонный парк. - 2007. - № 5-6. - С. 30-32.

7. Савчук, О.М. Эксплуатационные испытания полувагонов нового поколения [Текст] / О.М. Савчук [и др.] // Вагонный парк. - 2007. - № 7-8. - С. 28-30.

Ключевые слова: надежность, износ, план наблюдений, статистика, прогноз, число объектов, колесо.

\section{Аннотации}

Розглянуто плани експлуатаційних випробувань зразків нової вагонної техніки, методику визначень мінімальної кількості об'єктів спостережень за відмовами від зносу деталей вагона. Визначено мінімальну кількість залізничних коліс, необхіднихдля проведення експлуатаційних випробувань. Описано цілі, завдання та об'єкти дослідження експлуатаційних властивостей надійності вузлів і деталей вантажних вагонів у складі дослідних маршрутів.

Рассмотрены планы эксплуатационных испытаний образцов новой вагонной техники, методика определений минимального числа объектов наблюдений за отказами от износа деталей вагона. Определено минимальное количество железнодорожных колес, необходимых для проведения эксплуатационных испытаний. Описаны цели, задачи и объекты исследования эксплуатационных свойств надежности узлов и деталей грузовых вагонов в составе опытных маршрутов.

Discussed plans for operational testing of samples of the new wagon technology, methods of determining the minimum number of observations of objects failures from wear and tear of parts of the car. Determined the minimum number of railway wheels, needed to carry out performance tests. We describe the goals, objectives and objects of study performance characteristics of reliability parts and components of freight cars in the pilot routes. 